\title{
COAGULATION OF WOOD POLLUTANTS FROM MODEL WASTEWATER BY ALUMINIUM SALTS
}

\author{
J. Brovkina ${ }^{1}$, G. Shulga ${ }^{1}$, J. Ozolins ${ }^{2}$ \\ 1- Latvian State Institute of Wood Chemistry, 27 Dzerbenes Str., LV 1006, Riga, Latvia \\ ph: (+371)67545139, e-mail: julija.brovkina@gmail.com; shulga@junik.lv \\ 2- Riga Technical University, Faculty Of Material Science And Applied Chemistry, 14/24 \\ Azenes Str., LV 1048, Riga, Latvia \\ Ph.: (+371) 29241368, e-mail: juris_oz@inbox.lv
}

\begin{abstract}
One of the stages of raw material preparation for plywood producing is hydrothermal treatment of birch wood. Wastewater from plywood hydrothermal basin is characterized by the high degree of contamination. The basic contaminating component of this wastewater is lignin, hemicellulose and extractive substances (LES), which are the main reason of a high level of chemical oxygen demand (COD) and color of water. The main objective of the present study is to investigate the influence of aluminium sulfate, aluminium chloride and poly aluminium chloride dose on coagulation of LES from model wastewater. It was established that the influence of coagulant dose on LES removal can be described by 3 regions: first region - the process of coagulation does not take place; second region is characterized by the sharp increase of efficiency of LES removal and the third region corresponds to decrease of efficiency of LES removal at the increase of coagulant dose.
\end{abstract}

Keywords: coagulation, model wastewater, aluminium salts, dose, hemicellulose, lignin.

\section{Introduction}

The problem of wastewater treatment of hydrothermal basins that contain plenty of contaminating components such as lignin, hemicellulose and extractive substances of wood (LES) is very actual for the enterprises of the plywood industry. These substances give the high value of chemical oxygen demands (COD) and degree of colouring to the water flows. Traditionally these enterprises have the centralized system of biological purification that for a number of reasons in modern conditions can not suit ecological norms on emission in water objects. Change in purification technology and introduction of the additional stage of the physical and chemical purification from oxidation-prone part of organic matters of wood raw material delignification is the most perspective direction of emission decline on regulated property. From the other side, wood originated pollutants can be of interest in practice [1,2].

The coagulation method of purification in combination with the mechanical method of separation of the educed phase can be used as most accessible, not requiring considerable investments, and effective enough method. This process is carried out by adding hydrolyzing coagulants to the processed water. Chemical coagulants normally destabilise colloidal particles by four distinct mechanisms: double layer compression, charge neutralisation, enmeshment in a precipitate and inter - particle bridging [3].

In recent years the usage levels of coagulation method with the use of aluminium salts are increased, and judging by prediction, will increase. The study of regularity of coagulation process is therefore actual, as a method of purification of specific streams. Taking into account that the most high indexes of quality of wastewater purification are reached by adding of strictly certain optimal dose, then one of the stages in technology is determination of working dose of coagulant. For this purpose the researches have an important role, conducted on the model systems that imitate wastewater from plywood industry of hydrothermal basin [4].

The aim of this work is to study the coagulation process of LES in the presence of aluminium sulfate, aluminium chloride and poly aluminium chloride. 


\section{Materials and methods}

The model solution was described by $\mathrm{pH}$, density, LES content, COD and its color. The description of model solution is given in Table 1.

The characteristic of the model solution

\begin{tabular}{|c|c|}
\hline Parameters & Value \\
\hline $\mathrm{pH}$ & 9.02 \\
Density $\left(\mathrm{kg} / \mathrm{m}^{3}\right)$ & 995 \\
Optical density $(490 \mathrm{~nm})$ & 0.285 \\
Content of dry solids $(\mathrm{mg} / \mathrm{l})$ & 1400 \\
Colority $(\mathrm{mg} / \mathrm{lPt})$ & 746 \\
COD $(\mathrm{mgO} / \mathrm{l})$ & 1285 \\
\hline
\end{tabular}

Aluminium sulfate $\left(\mathrm{Al}_{2}(\mathrm{SO} 4)_{3} * 16 \mathrm{H}_{2} \mathrm{O}\right)$, aluminium chloride $\left(\mathrm{AlCl}_{3} * 6 \mathrm{H}_{2} \mathrm{O}\right)$ and polyaluminium chloride (Polypacs-30) were used as coagulants and the working solutions were prepared by dissolving of coagulants in distilled water depending on dose required. The process of coagulation was performed by mixing equal volumes of the coagulant and model solutions. A volume of the mixed system was $100 \mathrm{ml}$, and a time of mixing $-2 \mathrm{~min}$. The optimal terms of the LES removal in the presence of aluminium sulfate and chloride were studied, varying the dose of coagulant.

The efficiency of LES coagulation was defined after 2 hours of the system settling and filtration. The filtration was fulfilled through a paper filter "blue ribbon". The colloidal stability and coagulation of LES in the presence of aluminium salts was studied by spectrophotometry using Genesys(TM) 10 scanning spectrophotometer with scanning wavelength from 190 to $1100 \mathrm{~nm}$. The residual concentration of LES and birch lignin in the filtrate was defined by measuring filtrate optical density $(A)$ at the wavelength 490 and 280 $\mathrm{nm}$, respectively, using the preliminary received correlation curves. The filtrate color was defined by the method of photometry at the wavelength of $436 \mathrm{~nm}$; the results were reported in platinum-cobalt (PtCo) units, where a unit of color is equivalent to that produced by $1 \mathrm{mg} / \mathrm{l}$ of platinum in the form of the chloroplatine ion (ISO7887:1994). COD was determined by the oxidization of the received filtrate by adding potassium dichromate under the given reaction conditions. Calculation of the COD value from the amount of dichromate reduced (LVS ISO 6060:1989). A sludge volume index (SVI) gave information about dispersion system settling. By definition, the sludge volume index is the volume in $\mathrm{ml}$ occupied by $1 \mathrm{~g}$ of the settled dispersion after 30 min settling.

The efficiency of the model solution purification from LES, reduction of COD and color were calculated by using the following Eq. 1:

$$
\text { removal, } \%=\left[\frac{\left(C_{i}-C_{f}\right)}{C_{i}}\right] * 100
$$

where $C_{i}$ and $C_{f}$ are initial and final concentrations of LES, COD and the color.

\section{Results and discussions}

The study of influence of coagulant dose $\left(\mathrm{Al}_{2}\left(\mathrm{SO}_{4}\right)_{3}, \mathrm{AlCl}_{3}\right.$, Poly(AlCl) was conducted in a range $0-750 \mathrm{mg} / \mathrm{l}$. Data, reflecting the values of efficiency of LES removal at the use of aluminium salts (Fig.1 a, b, c), show general character of regularity. 


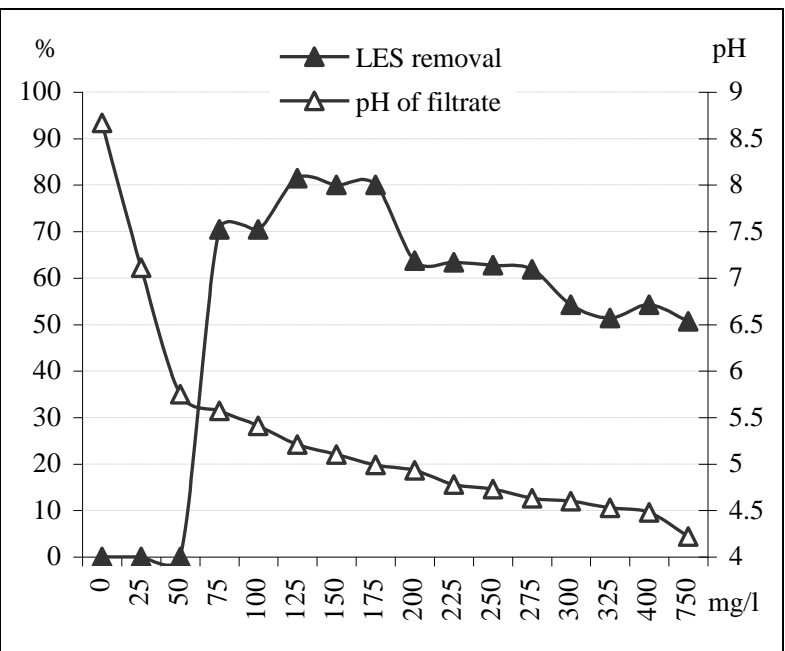

a)

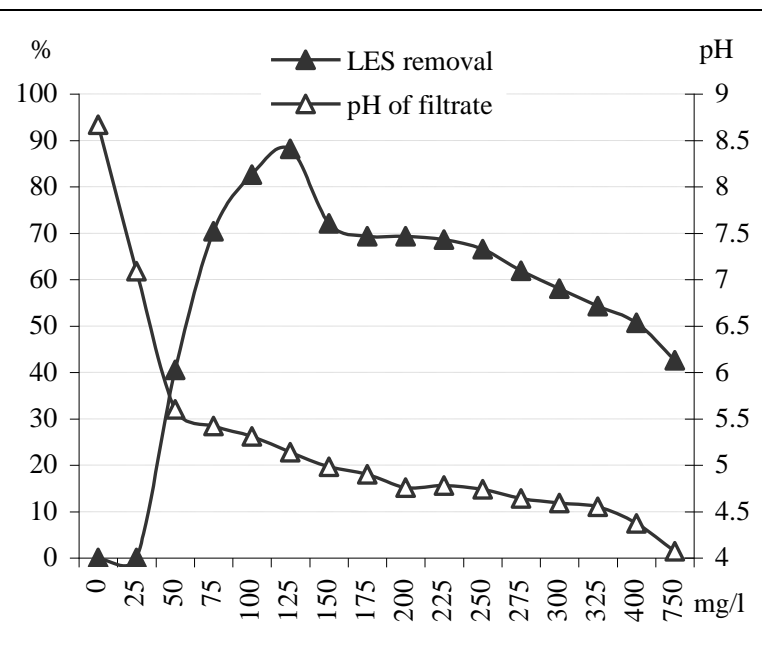

b)

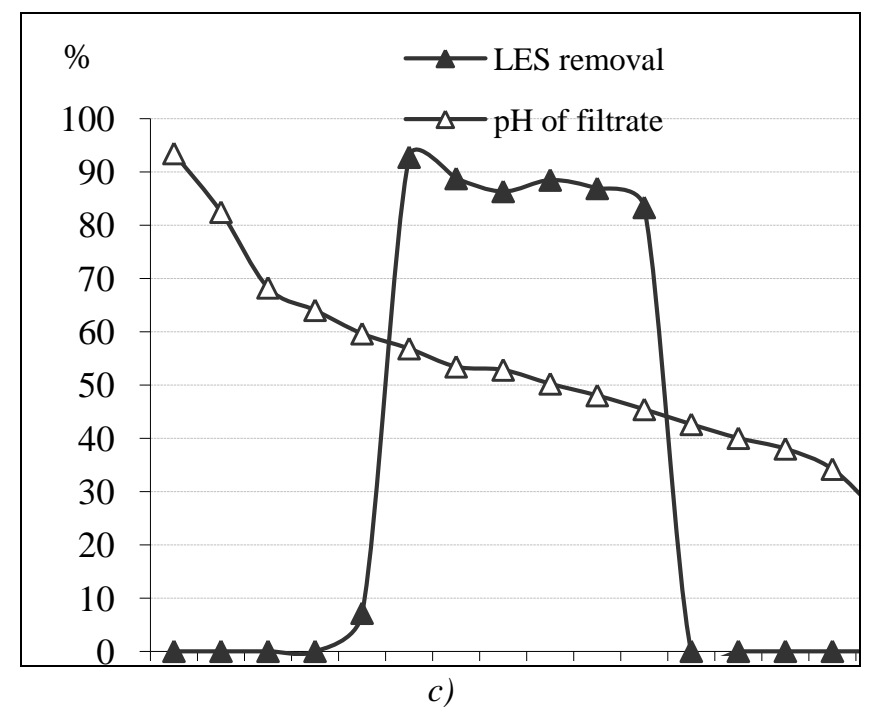

Fig.1. The effect of coagulant dose on the removal of $\mathrm{LES}$ and $\mathrm{pH}$ values of systems after settling and filtration: (a) $\mathrm{Al}_{2}\left(\mathrm{SO}_{4}\right)_{3}$, (b) $\mathrm{AlCl}_{3}$ and (c) Poly(AlCl)

In all three cases the increase of coagulant dose results in decrease of the $\mathrm{pH}$ system, that is related to the process of hydrolysis of aluminium salts, as a result of that there is a formation of slightly soluble hydroxides and simultaneously the hydrogen ions accumulate in the system that give to it the acid values of $\mathrm{pH}$ and are able to slow fullness of hydrolysis.

As it is seen from the pictures (Fig. $1 \mathrm{a}, \mathrm{b}, \mathrm{c}$ ), the influence of dose on a degree of the LES removal can be divided into 3 regions.

First region - the process of coagulation does not take place. This area is within the limits of doses of $\mathrm{Al}_{2}\left(\mathrm{SO}_{4}\right)_{3}$ to $50 \mathrm{mg} / 1$ (Fig.1.a), doses of $\mathrm{AlCl}_{3}$ is less than $25 \mathrm{mg} / \mathrm{l}$ (Fig.1.b) and doses of Poly $(\mathrm{AlCl})$ which do not exceed $75 \mathrm{mg} / \mathrm{l}$. This zone is characterized by conserving of LES colloid stability. The negatively charged particles of LES are stabilized due to forces of the mutual repulsion and hydrolysis products of aluminium salts with so small doses are incapable to neutralize the charges of LES particles.

Then the second region is characterized by the sharp increase of efficiency of LES removal: $\mathrm{Al}_{2}\left(\mathrm{SO}_{4}\right)_{3}$ is $50-175 \mathrm{mg} / \mathrm{l}$ (Fig.1.a), $\mathrm{AlCl}_{3}$ is $25-125 \mathrm{mg} / \mathrm{l}$ (Fig.1.b) and Poly(AlCl) is $75-250$ $\mathrm{mg} / \mathrm{l}$. On the curves of dependences there are maximums that correspond to the dose of 125 $\mathrm{mg} / \mathrm{l}$ for $\mathrm{Al}_{2}\left(\mathrm{SO}_{4}\right)_{3}, \mathrm{AlCl}_{3}$ and Poly $(\mathrm{AlCl})$. The next values of LES removal are reached: $\mathrm{Al}_{2}\left(\mathrm{SO}_{4}\right)_{3}-81.4 \%, \mathrm{AlCl}_{3}-88.1 \%$ and Poly $(\mathrm{AlCl})-92.7 \%$. In this zone the degree of stability 
of LES particles intensively decreases and a capacity for settling of appearing coagulants increases. Thus the values of $\mathrm{pH}$ filtrates are 5.2, 5.1 and 6.8 for $\mathrm{Al}_{2}\left(\mathrm{SO}_{4}\right)_{3}, \mathrm{AlCl}_{3}$ and Poly $\left(\mathrm{AlCl}_{3}\right)$, respectively. According [5,6,7], coagulation of LES with aluminium salts in this $\mathrm{pH}$ region is possible to interpret as follows: the process of hydrolysis of aluminium salts is leading by formation of the hydrolyzed forms of aluminium $\mathrm{AlOH}^{2+}, \mathrm{Al}(\mathrm{OH})_{2}{ }^{+}$and dimeric structures $\mathrm{Al}_{2}(\mathrm{OH})_{2}\left(\mathrm{H}_{2} \mathrm{O}\right)_{8}$ with a charge $4^{+}$for Poly $(\mathrm{AlCl})$. The formation of phase of $\mathrm{Al}(\mathrm{OH})_{3}$, the amount of which increases, begins and the density of its charge decreases as far as approaching to the isoelectric point of $\mathrm{Al}(\mathrm{OH})_{3}\left(\mathrm{pH}\right.$ 6.5-7.8). The insoluble $\mathrm{Al}(\mathrm{OH})_{3}$ formed from the hydrolysis of $\mathrm{Al}_{2}\left(\mathrm{SO}_{4}\right)_{3}$ appears at a lower $\mathrm{pH}$ (4.5-5.00 than that formed from $\mathrm{AlCl}_{3}$ and Poly(AlCl) (pH 6.0-7.0).

The third region corresponds to decrease of efficiency of LES removal at the increase of coagulant dose. It is connected with the insignificant sizes, density of appearing LES coagulants and the speed of their settling. As a rule, it is related to lowering of alkaline reserve and $\mathrm{pH}$ system below than possible level, namely change of $\mathrm{pH}$ value from the isoelectric point of aluminium salts, and also according to literary data [5], it can be related to the recharge of LES coagulants in the interval of $\mathrm{pH} 4.0$ - 5.0 (Fig.1.a, b) in presence of $\mathrm{Al}_{2}\left(\mathrm{SO}_{4}\right)_{3}$ and $\mathrm{AlCl}_{3}$ due to the increase of concentration of the positively-charged products of hydrolysis of coagulants. Also it should be noted (Fig.1.c) in the range of $\mathrm{pH} \leq 6.5$ and doses of Poly $(\mathrm{AlCl})>275 \mathrm{mg} / \mathrm{l}$ is related to stoppage of LES settling. It is explained [7] that at the high doses of Poly $(\mathrm{AlCl})$ in this area of $\mathrm{pH}$ there is a recharge of LES because of high content of hydrolysis products of $\mathrm{Poly}(\mathrm{AlCl})$ with a charge $4^{+}$, and the system saves sedimentation stability. It is necessary to mean that the increase of dose, comparatively with optimal, results not only in the overrun of coagulant but also to reduction of duration of useful work of sedimentation tanks.

In a table 2.there are data of efficiency of model solution purification from LES at the use of $\mathrm{Al}_{2}\left(\mathrm{SO}_{4}\right)_{3}, \mathrm{AlCl}_{3}$ and Poly( $\left.\mathrm{AlCl}\right)$ by a dose of $125 \mathrm{mg} / \mathrm{l}$.

One of the important indexes of coagulation quality is a capacity of the coagulation system for settling. The sludge volume index (SVI) gives information about settling of the coagulation system. The lower sludge index is the better settling. Value of sludge index for about $140 \mathrm{ml} / \mathrm{g}$ is usually considered acceptable to the satisfactory setting [6].

Table 2.

The efficiency of LES removal from model solution in the presence of aluminium coagulants at dose $125 \mathrm{mg} / \mathrm{l}$

\begin{tabular}{|l|c|c|c|c|c|c|}
\hline Coagulants & $\mathrm{pH}$ & $\begin{array}{c}\text { LES } \\
\text { removal, } \\
\%\end{array}$ & $\begin{array}{c}\text { Lignin } \\
\text { removal, } \\
\%\end{array}$ & $\begin{array}{c}\text { COD } \\
\text { removal, } \\
\%\end{array}$ & $\begin{array}{c}\text { Color } \\
\text { removal, } \\
\%\end{array}$ & $\begin{array}{c}\mathrm{SVI} \\
\mathrm{ml} / \mathrm{g}\end{array}$ \\
\hline $\mathrm{Al}_{2}\left(\mathrm{SO}_{4}\right)_{3}$ & 5.2 & 81.4 & 57.8 & 37.7 & 87.2 & 225 \\
\hdashline $\mathrm{AlCl}$ & 5.1 & 88.1 & 60.4 & 42.4 & 91.4 & 135 \\
\hdashline Poly(AlCl) & 6.8 & 92.7 & 58.4 & 40.9 & 83.8 & 51 \\
\hline
\end{tabular}

Presented data are practically comparable. However the maximal degree of purification is reached using $\mathrm{AlCl}_{3}$ and Poly $(\mathrm{AlCl})$. But it should be noted that Poly( $\left.\mathrm{AlCl}\right)$ at the identical dose addition does not cause the displacement of the $\mathrm{pH}$ system in a acid environment. And it is its distinctive advantage in comparison with a $\mathrm{Al}_{2}\left(\mathrm{SO}_{4}\right)_{3}$ and $\mathrm{AlCl}_{3}$, at the use of which $\mathrm{pH}$ filtrate is 5.0 on the average. In the working conditions of coagulation treatment of wastewater it can cause the necessity of the use of alkalizing reagents with the purpose of achievement of $\mathrm{pH}$ value of the purified water, corresponding to the norms of emission on local post-treatment of streams or centralized purifying stations $(\mathrm{pH}$ 6.2-7.2). Also it should be noted that a minimum value of SVI corresponds to the Poly $(\mathrm{AlCl})$ that characterizes the ability of excreted coagulants of LES to be settled and consolidated more intensively. 


\section{Conclusions}

Represented data show the regularity of LES coagulation from model wastewater. It was established that:

1. the increase of coagulant dose results in decrease of the $\mathrm{pH}$ system;

2. the influence of coagulant dose on LES removal can be described by 3 regions:

$\checkmark$ first region - the increase of dose does not cause the LES removal;

$\checkmark$ second region is characterized by the sharp increase of efficiency of LES removal;

$\checkmark$ third region - the increase of dose relatively optimal unfavorably affects the efficiency of LES removal from model solutions due to the displacement of values of $\mathrm{pH}$ in acid environments and lowering of alkaline reserve.

\section{Acknowledgement}

The researches leading to these results have received funding from the Latvian Council of Science for a grant $n^{\circ}$ 09-1610c, as well as from the European Social Fund within the project „Support for the implementation of doctoral studies at Riga Technical University

\section{References}

1. G. Shulga, J. Brovkina, T. Betkers, O. Aniskevicha, J. Ozolinšs. Relationship between composition of the lignin-based interpolymer complex and its structuring ability - Environmental Engineering and Management Journal, July/August 2008, Vol. 7. No.4. pp. 397-401.

2. G Shulga, V. Shakels, J. Brovkina, T. Betkers, J. Ozolinšs. Effect of rheological properties of the Ligninbased adhesive on aggregating of light-textured soil - Proceedings of 10th European Workshop on Lignocellulosics and Pulps, Stockholm, Sweden, August 26-29, 2008, pp. 356.

3. Mingquan Yan, Hailong Liu, Dongsheng Wang. Natural organic matter removal by coagulation: effect of kinetic and hydraulic power. Water Science and Technology: water supply, Vol. 9 (1), 2009, pp. 21-30.

4. J. Brovkina, G. Shulga, J. Ozolins. Recovery of lignin and extractive substances from the hydrolysate of model birch wood hydrolysis with aluminium salt. Chemine Technologija (Chemical Technology), Nr. 3-4 (56), 2010, p. 30-34.

5. Yu. M. Chernoberezhskii, D. Yu. Mineev, A. B. Dyagileva, A. V. Lorentsson and Yu. V. Belova. 2002. Recovery of Kraft Lignin from Aqueous Solutions with Oxotitanium Sulfate, Aluminum Sulfate, and Their Mixture. Russian Journal of Applied Chemistry, v. 75 (10), pp. 1730-1732.

6. С.Н. Линевич, С.В. Гетманцев. 2007. Коагуляционный метод водообработки, теоретичекие основы и практическое использование. Наука, Москва, 223 стр.

7. Barbara H. Wortley and Joe Steelhammer. (1990) Polyaluminum hydroxychloride application in neutral ph rosin sizing of paper. Mat. Res. Soc. Symp. Proc. v. 197, pp. 273-278. 